\title{
A study on the transverse changes resulting from treatment with Herbst connecting rods connected to splints*
}

\author{
Tania Stakowski
}

Directeur de mémoire : Claude CHABRE et Michel AMORIC / Paris VII

\begin{abstract}
The goal of this study was to discern the nature of the transverse changes that a treatment of sequence propulsions with Herbst connecting rods with no expansion component produced. Thirty one patients treated with Herbst connecting arms ${ }^{9,14,15}$ attached to splints that had no expansion screw were selected. After this propulsion stage, treatment for these patients was continued with appliances that also had no expansion component. On study models, we recorded distances between opposite first molars and measured angular variations of these teeth in the frontal plane. We compared these figures with Moorrees ${ }^{12}$ tables that furnish natural increase in transverse distance and used the Marshall ${ }^{11}$ table to give a base measurement of natural angular modifications ("torque"). Our results showed that a sequence of propulsion treatment created enough adaptation of the shape of the upper arch to make the application of expansion mechanics unnecessary.
\end{abstract}

\section{KEYWORDS}

Transverse adaptations

Propulsion

Splints

Herbst connecting rods

Address for correspondence:

T. STAKOWSKI,

149, rue de Rennes,

75006 Paris.

tania.stako@orange.fr

* The English version of this paper is not available; to read the French version, go to http://odf.edpsciences.org/10.1051/odf/2009006 